\title{
O PAPEL DAS MANIFESTAÇÕES ARTÍSTICAS CONTRA- HEGEMÔNICAS NA DESCONTRUÇÃO DO DISCURSO COLONIAL
}

\author{
Kyoma Oliveira \\ Universidade Federal Fluminense, Brasil
}

\begin{abstract}
Resumo: Os meios de expressão artística de maneira geral são considerados como caminho para se entrar na disputa por significação na conteporaneidade. Nesse artigo serão trabalhadas as produções musicais nas sociedades pós-coloniais, de que maneira a disputa pelo lugar de fala se dá, como os pressupostos estéticos se formam à luz das influências coloniais e qual o poder de capilaridade desses discursos proferidos de forma musicada. Para isso tomarei como exemplo a emergência do Reggae jamaicano na década de sessenta e a trajetória de seu maior representante Bob Marley; o reconhecimento internacional tardio das músicas e da estética forjada pelo multi-instrumentista nigeriano Fela Kuti; além do caso muito particular do Voukoum, movimento cultural com grande destaque para a música, criado e reproduzido na ilha caribenha de Guadalupe, ainda hoje portadora do título de departamento ultramarino francês.
\end{abstract}

Palavras-chave: Pós-colonialismo; música; estudos culturais

\section{Introdução}

Para pensarmos hoje, as narrativas referentes aos sujeitos subalternizados precisamos lançar mão de uma análise retrospectiva sobre a história moderno-contemporânea, mais especificamente sobre as práticas imperialistas desenvolvidas pelas potências europeias ao longo dos séculos XVI, XVII, XVIII, XIX e XX. Ingleses, franceses, espanhóis, portugueses, dentre outras potências europeias, em busca de expansão territorial e mercantil invadiram a Ásia, a América e posteriormente a África - essa última a princípio na procura de uma nova mão-de-obra escrava para substituir a nativa americana e subsequentemente, no final do século XIX, dividindo o território africano oficialmente para dar prosseguimento às explorações.

Para além da exploração econômica e violência física ocasionada via expansão imperialista às sociedades colonizadas, séculos de discursos de hegemonia, reproduzidos a fim de convencer o indivíduo colonial a respeito de sua subalternidade, permanecem intrinsecamente conectados aos pensamentos dos sujeitos contemporâneos, atores das sociedades anteriormente dominadas. É sobre essa temática específica que alguns teóricos dos estudos pós-coloniais se propõem a refletir.

Os estudos pós-coloniais incorporam o legado das teorias de classe presente no marxismo juntamente com diretrizes presentes na teoria culturalista, onde, para além 
da diferenciação classista, a opressão dos indivíduos marginalizados se sedimenta via distinção cultural e fixidez do pensar.

No caso específico desse artigo me aterei a três pensadores: Césaire, Fanon e Bhabha. A fim de traçar um paralelo entre suas formas de pensar/interferir o/no campo social e posteriores manifestações artísticas periféricas também desencadeadas pelo discurso colonial.

Os meios de expressão artística de maneira geral são considerados como caminho para se entrar na disputa por significação no espaço social. A literatura colonial, por exemplo, encontra-se presente tanto nas análises narrativas de Homi Bhabha quanto de Edward Said. Através de análises comparativas de produções como Versos Satânicos e Mil e Uma Noites com a realidade social encontrada, esses autores vieram a contribuir para a reflexão acerca do discurso colonial.

Nesse artigo serão trabalhadas as produções musicais nas sociedades pós-coloniais, de que maneira a disputa pelo lugar de fala se dá, como os pressupostos estéticos se formam à luz das influências coloniais e qual o poder de capilaridade desses discursos proferidos de forma musicada. Para isso tomaremos como exemplo a emergência do Reggae jamaicano na década de sessenta e a trajetória de seu maior representante Bob Marley; o reconhecimento internacional tardio das músicas e da estética talhada pelo multi-instrumentista nigeriano Fela Kuti; além do caso muito particular do Voukoum, movimento cultural com grande destaque para a música, criado e reproduzido na ilha caribenha de Guadalupe, ainda hoje portadora do título de departamento ultramarino francês.

\section{Um histórico do contra-discurso}

O poeta, dramaturgo e ensaísta martinicano Aimé Césaire em seu "Discurso Sobre o Colonialismo" ${ }^{1}$ busca tratar o colonialismo para além das, não menos importantes, ações violentas de usurpação social, analisando discursos proclamados por diferentes atores sociais de colônias francesas. Dentre suas críticas podem-se elencar três principais: à teoria tropicalista presente no campo da geografia, à teoria ontológica cunhada na teologia e à teoria referente ao complexo de dependência, do psicanalista francês Octave Mannoni. Assim como Césaire, dedicamos um espaço maior a essa última.

\footnotetext{
${ }^{1}$ Artigo escrito para a revista francesa Presences Africaines em 1950, e cinco anos depois revisto e expandido para publicação na Éditions Réclame.
} 
Em seu trabalho feito em Madagascar, Mannoni conclui que os Malgaxes $^{2}$ são um exemplo de grupo assolado por tal complexo.

O senhor Mannoni diagnostica "O Malgaxe não tenta sequer imaginar semelhante situação de abandono... Não deseja autonomia pessoal nem livre responsabilidade.” (Bem o sabeis, vejamos. Esses pretos não imaginam sequer o que é a liberdade. Não a desejam, não a reivindicam. São os instigadores brancos que lhes metem isso na cabeça. E se lha dessem, não saberiam o que fazer dela.) (Césaire 1978, p. 47)

Em sua análise sobre o trabalho desenvolvido por Mannoni, Césaire conclui, ironicamente, que sempre que tinha suas ideias questionadas com relação à barbárie colonial europeia, o psicanalista francês ponderava as ações do governo francês. Citando Mannoni, Césaire segue:

Seguindo caminhos muito clássicos, estes Malgaxes transformam os seus santos em mártires, os seus salvadores em bodes expiatórios; queriam lavar os seus pecados imaginários no sangue dos seus próprios deuses. Estavam prontos, mesmo a tal preço, ou melhor, só a esse preço, a inverter mais uma vez a sua atitude. Um aspecto dessa psicologia dependente seria a conveniência, pois que ninguém pode ter dois amos, em sacrificar um deles ao outro. A fracção mais transtornada dos colonialistas de Tananarive compreendia confusamente o essencial desta psicologia do sacrifício e reclamava as suas vítimas. Assediavam o Alto-Comissionário, assegurando que, se lhes concedessem o sangue de alguns inocentes, 'toda a gente ficaria satisfeita'. Esta atitude humanamente desonrosa, fundava-se numa percepção, grosso modo bastante certa, das perturbações emocionais que a população dos altos canais atravessava." Daí a absolver os colonialistas sedentos de sangue, não vai, evidentemente, mais que um passo. (Césaire 1978, p. 48)

No decorrer de sua análise Manoni deixa de lado parte fundamental da convivência entre os sujeitos coloniais: a capacidade de agência dos colonizados. Os locais de recepção e rearticulação desses sujeitos subjugados são, inclusive, elemento fulcral de análise dos estudos pós-coloniais. Local de rearticulação denominado por Bhabha (2013) zona intersticial, espaço onde a interação entre diferentes práticas culturais resultam numa terceira, híbrida. Mais à frente, nas análises do surgimento das manifestações musicais, a idéia desse entre-lugar existente no campo social será retomada tornando clara a necessidade de evidenciar esse espaço intervalar de contato entre as culturas coloniais.

O modo com que os três teóricos pós-coloniais se colocam frente aos indivíduos de seus estudos é um ponto em comum entre suas análises. Por se tratarem, eles próprios, de

\footnotetext{
2 Os malgaxes compreendem o grupo étnico de metade da população da ilha de Madagascar, na costa leste da África.
} 
sujeitos coloniais, suas análises partem de um ponto diferente de falas acadêmicas tradicionais. $\mathrm{O}$ antilhano Frantz Fanon, por exemplo, formado em psiquiatria e filosofia na França, participou ativamente da luta pela libertação da Argélia, onde observou os processos de subjetivação tecidos pelo colonizador e introjetados pelos colonizados em especial nos que fazem referência a seus corpos e pele - que já havia identificado anteriormente na Martinica, colônia francesa onde nasceu e cresceu, e no período em que serviu o exército francês.

Fanon (1952) questiona de dentro da academia a tradição metropolitana sobre as mentalidades "primitivas". Em sua posição de “intelectual assimilado" repensa o posicionamento dos indivíduos colonizados encarados como objeto do discurso. Visando a descolonização das mentes, faz a defesa de que a história deve ser re-escrita e reinterpretada, de maneira que os indivíduos-objeto se desloquem para uma posição de agência.

Nessa época, desorientado, incapaz de estar no espaço aberto com o outro, com o branco que impiedosamente me aprisionava, eu me distanciei para longe, para muito longe do meu estar-aqui, constituindo-me como objeto. O que é que isso significava para mim, senão um desalojamento, uma extirpação, uma hemorragia que coagulava sangue negro sobre todo o meu corpo? No entanto, eu não queria esta reconsideração, esta esquematização. Queria simplesmente ser um homem entre outros homens. (Fanon, 2008, p. 106)

Enquanto sujeito diaspórico, Fanon a todo o momento aborda a produção subjetiva introjetada pelo negro como parte de sua trajetória, seu reconhecimento acerca da própria negritude é um ponto crucial para o desenvolvimento de suas reflexões.

Como assim? Quando então eu tinha todos os motivos para odiar, detestar, rejeitavam-me? (...) Desde que era impossível livrar-me de um complexo inato, decidi me afirmar como Negro. Uma vez que o outro hesitava em me reconhecer, só havia uma solução: fazer-me conhecer. (Fanon, 2008, p. 108)

A auto-afirmação das identidades coloniais é ilustrada, sobretudo no caso do afrobeat nigeriano e da manifestação guadalupense. O reconhecimento das identidades transculturadas é o primeiro passo para o ato de resistência para com o discurso colonial e seus estereótipos.

Segundo Bhabha (2013), a consolidação do estereótipo e seu caráter ambivalente têm papel fundamental no entendimento da teoria do poder/discurso colonial, existe a necessidade de sempre se repetir posicionamentos para que esses sejam assimilados como reais, e para que as proposições introjetadas sejam mantidas. Em dado momento o autor se propõe a analisar o estereótipo pelo viés do fetichismo, nesse momento a 
ambivalência se faz presente também no processo de reconhecimento do outro, "O fetiche ou estereótipo dá acesso a uma "identidade" baseada tanto na dominação e no prazer quanto na ansiedade e na defesa, pois é uma forma de crença múltipla e contraditória em seu reconhecimento da diferença e recusa da mesma.” (Bhabha, 2013, p. 130).

A forma com que a alteridade é ou não balizada nas reflexões sobre a formação de um pensamento colonial nos auxilia a pensar de que forma as práticas discursivas de hierarquização cultural e racial se estabeleceram no decorrer da história. O objetivo do discurso colonial é vincular a subalternidade do indivíduo colonizado à sua etnia ou cultura para que a partir daí justifique-se intervenções e dominações em diferentes esferas de atividade para os mais diversos fins (Bhabha, 2013, p.124). Com a reprodução constante dessa narrativa colonial, uma memória oficial surge e se sedimenta com o passar do tempo, de modo que algumas categorias classificatórias engendradas paulatinamente no decorrer de um determinado período histórico são encaradas de maneira naturalizada pelo sujeito colonial. A respeito disso, Fanon ainda se coloca:

De um dia para o outro, os pretos tiveram de se situar diante de dois sistemas de referência. Sua metafísica ou, menos pretensiosamente, seus costumes e instâncias de referência foram abolidos porque estavam em contradição com uma civilização que não conheciam e que lhes foi imposta. O negro em seu país, em pleno século $\mathrm{XX}$, ignora o momento em que sua inferioridade passa pelo crivo do outro... (Fanon, 2008, p. 104)

Partindo do princípio que os conceitos de narrativa e memória são indissociáveis e que a memória é um fenômeno coletivo e social, a partir de interações sociais, projeções no presente de acontecimentos passados podem ocorrer, uma espécie de memória herdada. Sendo assim a memória construída gradativamente em determinados processos históricos é objeto de um constante trabalho de manutenção para que a visão recortada e enquadrada dos acontecimentos seja mantida de maneira a não gerar conflito entre grupos hegemônicos e subalternos (Pollak, 1992).

Posto isso, o primeiro passo para uma mudança efetiva no campo social, seria a compreensão desse processo de construção da memória oficial e a partir daí, se colocar na disputa por significações para obtenção de reconhecimento. Os três exemplos analisados a seguir ilustram algumas maneiras encontradas pelos indivíduos marginalizados de entrar na nessa disputa. 


\section{O reggae como porta de entrada para ordem do discurso}

(...) em toda sociedade a produção do discurso é ao mesmo tempo controlada, selecionada, organizada e redistribuída por certo número de procedimentos que têm por função conjurar seus poderes e perigos, dominar seu acontecimento aleatório, esquivar sua pesada e temível materialidade. Em uma sociedade como a nossa, conhecemos, é certo, procedimentos de exclusão. O mais evidente, o mais familiar também, é a interdição. Sabe-se bem que não se tem o direito de dizer tudo, que não se pode falar de tudo em qualquer circunstância, que qualquer um, enfim, não pode falar de qualquer coisa. Tabu do objeto, ritual da circunstância, direito privilegiado ou exclusivo do sujeito que fala: temos aí o jogo de três tipos de interdições que se cruzam, se reforçam ou se compensam, formando uma grade complexa que não cessa de se modificar. (Foucault, 1996, pp. 8-9)

Quando nos referimos ao direito de fala de grupos subalternos, o conceito da interdição apresentado por Foucault (1996) se faz necessário para uma análise mais profunda. Os discursos coloniais estiveram sempre permeados pelo direito privilegiado do sujeito que fala, no caso o colonizador. Muito devido a esse aspecto, em alguns momentos históricos, grupos colonizados se propuseram a disputar o direito de entrada na ordem do discurso para, a partir daí, lutar pelo direito de significar, produzir sentido e obter reconhecimento (Bhabha, 2013). Tais disputas se deram de diferentes maneiras.

$\mathrm{Na}$ Jamaica, por exemplo, a religião e a música serviram como importantes ferramentas na luta por esses direitos. O rastafarianismo e o reggae fazem parte, ainda hoje, do manancial de elementos que compõe identitariamente a Jamaica. O reconhecimento dessas duas práticas se deu nas décadas de sessenta e setenta, quando os cidadãos jamaicanos que viviam à margem da sociedade se propuseram a produzir gêneros musicais nacionais.

Com a independência alcançada em 1962, a sociedade jamaicana, nesse momento mais do que nunca, buscava produções musicais que dialogassem com a realidade social de ex-colônia inglesa. Durante algum tempo as rádios locais executavam em grande número as músicas americanas e inglesas. O Rhythm And Blues, por exemplo, foi um dos ritmos estrangeiros que mais influenciou o surgimento do $S k a$, historicamente reconhecido como o primeiro gênero urbano e popular jamaicano. O andamento das músicas era acelerado e os instrumentistas virtuosos. Com relação a esses últimos, pertenciam em grande parte ao movimento Rastafári, prática religiosa baseada na bíblia, porém interpretada sob o ponto de vista da população jamaicana afrodescendente. A terra prometida para os rastafáris era a Etiópia e o imperador etíope a representação terrena de Jah (o deus da religião).

Aqui um exemplo claro do movimento de apropriação desempenhado pelos jamaicanos. Ao estabelecerem contato com o texto sagrado do cristianismo, alterações na história escrita foram desenvolvidas. A passividade descrita por Manoni é 
problemática e desonesta tendo em vista que grande parte das práticas culturais desenvolvidas numa sociedade colonial se estabelece à luz de larga hibridação. Segundo Hall:

(...) o rastafarismo se representou como um "retorno". Mas aquilo a que ele nos "retornou" foi a nós mesmos. Ao fazê-lo, produziu "a África novamente" - na diáspora. O rastafarismo aproveitou muitas "fontes perdidas" do passado. Mas sua relevância se fundava na prática extraordinariamente contemporânea de ler a Bíblia através de sua tradição subversiva, sua não ortodoxia, seus apócrifos; lendoa ao revés, de cabeça para baixo, voltando o texto contra si mesmo. A "Babilônia" de que ele falava, onde as pessoas ainda sofriam, não era o Egito, mas Kingston - e depois, quando o nome foi sintagmaticamente estendido para incluir a Polícia Metropolitana, os bairros de Brixton, Handsworth, Moss Side e Notting Hill. O rastafarismo exerceu um papel crucial no movimento moderno que tornou "negras", pela primeira vez e irremediavelmente, a Jamaica e outras sociedades caribenhas. Numa tradução ulterior, essa doutrina e discurso estranhos "salvaram" as jovens almas negras da segunda geração de migrantes caribenhos nas cidades britânicas nos anos 60 e 70 e deu-lhes orgulho e autoconhecimento. Nos termos de Frantz Fanon, eles descolonizaram as mentes. (Hall, 2003, p.43)

Mesmo com o engajamento religioso dos integrantes, as letras das canções de $S k a$, em sua maioria, não tinham compromisso com a realidade política da ilha. Somado a isso, o fim do grupo que obteve maior reconhecimento no gênero, os Skatalites, o Ska perdeu parte de seu ímpeto inicial.

Outro precursor do Reggae é o Rocksteady, o gênero, que consistia esteticamente na diminuição do andamento rápido característico do $S k a$. Já as letras das canções eram voltadas para temas sociais e políticos, fato que fez com que os Rude Boys ${ }^{3}$ se identificassem com o gênero. Uma das bandas representantes do gênero, The Wailers ${ }^{4}$, acompanhou Bob Marley durante toda sua carreira.

A transição entre o Rocksteady e o Reggae é um tanto nebulosa. Diferentes versões são contadas, porém o que efetivamente pode-se dizer, é que neste último os andamentos das canções ficaram ainda mais lentos. Assim como nos outros dois estilos nacionais, a acentuação rítmica da guitarra e/ou do teclado era deslocada do tempo forte para o tempo fraco do compasso ou ainda do próprio tempo, acarretando num suingue

\footnotetext{
${ }^{3}$ Rude boy, rudeboy, rudie, rudi ou rudy é um termo usado para designar os delinquentes juvenis e criminosos na Jamaica nos anos 6o, e desde então tem sido usado em outros contextos. No final dos anos 70, durante o revival do ska na Inglaterra os termos rude boy, rude girl e outras variações foram usados para denominar os fãs desse gênero musical, e essa nova definição continuou a ser usada na subcultura da terceira onda do ska. No Reino Unido, nos anos 2000, os termos rude boy e rude girl têm sido usados para se referir às pessoas que estão envolvidas na cultura de rua, similar à gangsta ou badman.

${ }^{4}$ A banda figurou nas três fases musicais da Jamaica (ska, rocksteady e reggae).
} 
recorrente em estilos contra métricos. Além disso, tanto no Rocksteady quanto no Reggae, diferentemente dos arranjos convencionais, o contrabaixo e a bateria tinham destaque nas equalizações 5 . Em se tratando de um ritmo não hegemônico e póscolonial, essas idiossincrasias estéticas podem ser encaradas como alegorias referentes aos indivíduos que buscam romper com o status quo e entrar na ordem no discurso.

O primeiro disco a ganhar notoriedade, até então, na nova cena Reggae, é o Catch $A$ Fire, de Bob Marley \& The Wailers. Como informa o próprio nome do disco, "os lamentadores" haviam chegado para esquentar não só o cenário musical, mas também político da Jamaica. Nas duas primeiras faixas: “Concrete Jungle" e "Slave Driver" a temática das amarras mentais deixadas por anos de colonização se faz recorrente.

(...) Everytime I hear the crack of the whip/My blood runs cold/I remember on the slave ship/How they brutalised our very souls/Today they say that we are free/Only to be chained in poverty/Good God, I think it's all illiteracy/It's only a machine that make money (...) 67

Ainda no mesmo ano, a banda lança o disco Burning com letras ainda muito afiadas e impugnadoras. As temáticas circulavam em torno do chamado direcionado à população periférica jamaicana, pela luta por seus direitos, além de brados subversivos. Algumas das músicas que alcançaram maior notoriedade são "I Shot the Sherif", difundida internacionalmente por Eric Clapton, e "Get Up Stand Up”, com o incisivo refrão: “Get up, stand up: stand up for your rights! Get up, stand up: don't give up the fight!" 8

Com o transcorrer da carreira, além de mudanças na formação do grupo, o discurso das canções de Bob Marley e os Wailers foi se transformando. A espiritualidade estava cada vez mais aflorada nas composições de Bob Marley, e o confrontamento proposto de maneira mais objetiva nos dois primeiros discos passou a se misturar com o discurso mais pacifista. A dedicação de Bob Marley cada vez maior a cultura Rastafári pode ser notada em diversas canções, onde Jah e o amor são exaltados frequentemente. No álbum lançado em 1976 - Rastaman Vibration - um discurso de Hailé Selassié, o

\footnotetext{
${ }^{5}$ No Brasil, a bateria e a percussão são apelidadas, no campo musical, de "cozinha” (há quem considere o contrabaixo parte dessa categoria). O papel deles em diversos ritmos é manter uma base rítmica coesa para que os demais instrumentos façam as melodias principais, secundárias ou improvisadas. Essa distinção entre os instrumentos rítmicos e harmônicos/melódicos é feita de maneira naturalizada, busco aqui apontar para uma possível discussão sobre a subalternidade velada acerca dos instrumentos que não trabalham, essencialmente, com os padrões melódicos e harmônicos ocidentais.

6 Artista: Bob Marley and The Wailers (1973) Música: Slave Driver Gravadora: Island Records.

7 (...) Toda vez que eu ouço o estalar do chicote/Meu sangue corre frio/ Eu me lembro no navio negreiro/Como eles brutalizaram nossas almas/ Hoje eles dizem que nós somos livres/Apenas para sermos acorrentados à pobreza/Bom Deus, eu acho que é tudo ignorância/É só uma máquina que faz dinheiro (...)

8 "Levante, lute: lute pelos seus direitos! Levante, lute: não desista da luta!"
} 
imperador da Etiópia, foi musicado, resultando na canção War, mais um clássico na carreira de Bob Marley e os Wailers.

Until the philosophy which hold one race/Superior and another inferior/Is finally and permanently discredited and abandoned/Everywhere is war, me say war./That until there are no longer first class/And second class citizens of any nation/Until the color of a man's skin/Is of no more significance than the color of his eyes/Me say war./That until the basic human rights are equally/Guaranteed to all, without regard to race/Dis a war./That until that day/The dream of lasting peace, world citizenship/Rule of international morality/Will remain in but a fleeting illusion/To be pursued, but never attained/Now everywhere is war, war./And until the ignoble and unhappy regimes/That hold our brothers in Angola, in Mozambique,/South Africa sub-human bondage/Have been toppled, utterly destroyed/Well, everywhere is war, me say war./War in the east, war in the west/War up north, war down south/War, war, rumours of war./And until that day, the African continent/Will not know peace, we Africans will fight/We find it necessary and we know we shall win/As we are confident in the victory./Of good over evil, good over evil, good over evil/Good over evil, good over evil, good ever evil. 910

O discurso proferido em junho de 1930 na Liga das Nações em Genebra, na Suíça, se faz pertinente ainda hoje. Nos anos 70, em uma Jamaica recém-independente e atravessada por introjeções de um discurso colonial centenário fazia ainda mais sentido. Quanto à forma da canção, percebe-se que o arranjo instrumental desempenha o papel de suporte para o conteúdo discursivo. A canção dura pouco mais de sete minutos e as variações instrumentais são praticamente nenhuma, a opção por essa estética atribui à música um caráter hipnótico, quase ritualístico.

No penúltimo disco de Marley com os Wailers, as letras têm um forte cunho político, fazendo referência aos processos de independência na África. Canções como Zimbabwe e Africa Unite mostram a preocupação com a população africana para além da Jamaica, além de certa afinidade do compositor para com os ideais pan-africanistas, em maior evidência nos países em que a luta por independência se desenvolvia. Em seu último

\footnotetext{
${ }^{9}$ Artista: Bob Marley And The Wailers. Música: War (1976) Gravadora: Island Records.

10 Até que a filosofia que torna uma raça superior/E outra inferior, seja finalmente permanentemente/Desacreditada e abandonada haverá guerra/Eu digo guerra/Até que não existam mais cidadãos/De $1^{\mathrm{a}}$ e $2^{\mathrm{a}}$ classe em qualquer nação/Até que a cor da pele de um homem/Não tenha maior significado que a cor/Dos seus olhos haverá guerra/Até que todos os direitos básicos/Sejam igualmente garantido para todos/Sem privilégios de raça, terá guerra/Até esse dia o sonho da paz final/Da almejada cidadania e o papel/Da moralidade internacional/Não será mais que mera ilusão a ser percebida e nunca atingida/Por enquanto haverá guerra, guerra/Até que os ignóbeis e infelizes regimes/Que prendem nossos irmãos em Angola/Em Moçambique, África do Sul escravizada/Não mais existam e sejam destruídos/Haverá guerra, eu disse guerra/Guerra no leste, guerra no oeste/guerra no norte, Guerra no sul/guerra, guerra, rumores de guerra/E até esse dia, o continente africano/conhecerá a paz Nós africanos lutaremos/Achamos isto necessário e sabemos que devemos ganhar/E estamos confiantes na vitória/O bem sobre o mal, bem sobre o mal/O bem sobre o mal, bem sobre o mal.
} 
disco lançado em vida - o Uprising - o cantor emplaca mais alguns sucessos sem perder o teor crítico de seu trabalho. Em Redemption Song, a última faixa do lado b do disco, Bob Marley mais uma vez aborda a questão das amarras mentais que assola os jamaicanos, nos versos "Emancipate yourselves from mental slavery/None but ourselves can free our minds" "11, o compositor sintetiza o que os teóricos pós-coloniais, como Bhabha, Fanon, Césaire e o próprio Hall desenvolveram em suas obras. Em comum entre todos eles, há o fato de serem sujeitos coloniais, portanto atravessados por valores e significados oriundos de suas respectivas experiências nas colônias, porém com um caráter crítico em seus discursos e difundindo o resultado de suas vivências e reflexões por diferentes meios.

Como ponto diferencial do discurso do compositor há o poder de capilaridade de sua música. Bob Marley não foi apenas um dos maiores representantes do Reggae de todos os tempos, como o artista periférico a atingir o maior sucesso na indústria musical. Os fatores mais diversos podem ser levados em conta para análise desse sucesso inédito como, por exemplo, a inovação estética presente no gênero musical, a língua em que as canções eram cantadas, a diáspora populacional afro-caribenha e a facilidade de assimilação de narrativas que os versos rimados propiciam. Tentar conjecturar os motivos do sucesso do Reggae pode requerer uma série de outros levantamentos e análises que não pretendo fazer nesse artigo, o que nos interessa aqui é a capacidade de ressonância e longevidade que a prática musical proporcionou ao discurso emergente.

\section{O caso do afrobeat}

He be say you be colonial man/You don be slave man before/Them don release you now/But you never release yourself/I say you fit never release yourself/Colomentality/He be say you be colonial man/You don be slave man before/Them don release you now/But you never release yourself (...) ${ }^{12} 13$

Na mesma década de setenta, do outro lado do Atlântico, a Nigéria, independente da Inglaterra há 10 anos, também contava com a insatisfação de algumas camadas da população para com a ordem política e social estabelecida. Em 1966, após dois golpes militares sucessivos, instaurou-se no país um regime totalitário. Depois de 46 anos sob o domínio colonial inglês, o discurso de subalternidade estava introjetado nos indivíduos. Aliado a isso, houve a dispersão populacional em direção a diferentes

\footnotetext{
11 “Libertem-se da escravidão mental/Ninguém além de nós pode libertar nossas mentes."

12 Artista: Fela Anikulapo Kuti and The Africa 70 (1977) Álbum: Opposite People Música: Colonial Mentality. Gravadora: Decca Afrodesia.

13 Ele diz que você é um homem colonial/ Você nunca foi um homem escravo antes/Eles não te libertam agora/ Mas você nunca se liberta/Eu disse você encaixa nunca se liberta/Colo-mentalidade/ Ele diz que você é um homem colonial/Você nunca foi um homem escravo antes/Eles não te libertam agora/ Mas você nunca se liberta (...).
} 
lugares do globo, seguida por um rejuntamento violento e impensado: caracterizados pelos Estados africanos, um conjunto de entidades administrativas incoerentes e problemáticas responsáveis por gerar uma série de conflitos internos. Um dos resultados foi o clamor pela mudança social, pretendida por diversos grupos. É nessa conjuntura que nasce o Afrobeat.

Seu criador, Fela Kuti, músico multi-instrumentista nigeriano, busca relatar e questionar todos os séculos de violência a que o continente africano foi submetido. Diferentemente de Bob Marley, Fela foi responsável por criar o seu gênero musical. Sua trajetória de vida está diretamente ligada às matrizes escolhidas para a criação do Afrobeat. Nascido em Lagos, ex-capital nigeriana, na adolescência se mudou para a Inglaterra para completar seus estudos musicais, e posteriormente fez algumas incursões por Gana, onde tentava solidificar a carreira. Nos anos 60 Fela passou dez meses com sua banda, de maneira clandestina nos Estados Unidos. Lá foi apresentado a alguns movimentos negros e se conscientizou da importância de cantar a África e militar por ela quando voltasse à Nigéria.

O gênero, segundo o próprio, consistia em uma mistura entre o jazz, a salsa e o Soul norte americano (cuja referência para Fela, tanto política quanto musical, era James Brown) com Juju e Highlife, dois gêneros pop tocados na própria Nigéria e em Gana, além de cantos tradicionais africanos. O grande virtuosismo e musicalidade de Fela Kuti e sua banda, The Africa 70 e posteriormente The Egypt 8o, originou canções enormes e hipnóticas com grandes sessões de improviso, timbres viscerais, letras politizadas e objetivas que atacavam diretamente as classes dominantes, o regime ditatorial nigeriano e as medidas neoliberais que usurpavam o país. Sem meias palavras, Fela não hesitava em citar nomes de ditadores nem das multinacionais que criticava.

Before them come force us away as slaves/During the time them come force us away as slaves/Na European man, na him dey carry shit/Na for them culture to carry shit/During the time them come colonize us/Them come teach us to carry shit/Long, long, long, long time ago/African man we no dey carry shit/Na European man teach us to carry shit/Say am, say am!/Many foreign companies dey Africa carry all our money go/Many foreign companies dey Africa carry all our money go/Them go write big English for newspaper, dabaru we Africans/Them go write big English for newspaper, dabaru we Africans (...) Them go dey cause confusion (Confusion!) Cause corruption (Corruption!) Cause oppression (Oppression!) Cause inflation (Inflation!). ${ }^{14} 15$

14 Artista: Fela Anikulapo Kuti and The Africa 70 (1979) Música: I.T.T. (International Thief Thief) Gravadora: Kalakuta. 
Devido ao cunho altamente político das canções e ao tempo de duração de cada uma delas, a maior parte de seus discos foi lançado de forma independente, visto que para assinar contrato com uma grande gravadora, seu trabalho teria de ser enquadrado e deixaria de transmitir sua mensagem.

Transcendendo o campo musical, Fela lidava a todo o momento com a subversão da ordem sociopolítica nacional. A África herdada, denominada por ele como "África da Impostura", devia ser reformada, segundo Fela, pelos próprios africanos. Em uma de suas tentativas, o músico fundou a "República de Kalakuta", uma comunidade, onde ele era o presidente, localizada em um gueto de Lagos. Esse foi o seu modo de refazer "sua" África ${ }^{16}$.

A imprensa local e internacional, buscando desqualificar o discurso político de Fela Kuti, tratava Kalakuta como um antro orgiástico, onde o ativista morava com prostitutas, viciados e bandidos: a verdadeira "Babilônia”, em Lagos.

A postura desinibida e casual de Fela a respeito das relações sexuais e sua afeição natural à nudez, somadas à visão negativa criada pelo seu uso contumaz de maconha, sem dúvida, cutucaram os preconceitos vitorianos das conservadoras elites africanas pós-independência (...). Assim, em uma versão calculadamente sexualizada, ele foi convenientemente reduzido pela mídia a caricatura vazia de hedonista errante, polígamo fanfarrão e maconheiro desajustado. (Moore, 2011, p. 19)

Aqui, para além da lógica de interdição do discurso, que se faz presente na busca de um esvaziamento de sentido do sujeito colonial, outro exemplo de exclusão se faz presente: a separação e rejeição à luz da oposição "razão e loucura" (Foucault, 1996, p. 10). Posto que Fela Kuti estava subvertendo uma ordem social vigente, a fim de gerar mudanças no quadro sociopolítico nigeriano, imputá-lo a loucura é um modo de desqualificar seu discurso.

Pode-se aqui perceber a importância da ferramenta do discurso nas propostas de dominação. Neste caso específico, - colonial e pós-colonial - o quadro se mostra mais claro por motivos já citados anteriormente, porém em situações contemporâneas, com

\footnotetext{
15 Antes deles virem forçar-nos para longe como escravos/ Durante o tempo em que eles vieram forçar-nos como escravos/ Não o homem europeu. não eles não carregam merda/ Não é pra cultura deles carregar merda/Durante o tempo em que eles vieram nos colonizar/Eles vieram nos ensinar a carregar merda/Nenhum homem europeu nos ensina a carregar merda/Diga eu sou, diga eu sou!/ Muitas empresas estrangeiras deles na África carregaram todo o nosso dinheiro/!/ Muitas empresas estrangeiras deles na África carregaram todo o nosso dinheiro/ Eles vão escrever em grande inglês para os jornais, dabaru nós africanos/ Eles vão escrever em grande inglês para os jornais, dabaru nós africanos/(...)/Eles vão eles causam confusão (confusão!) Causam corrupção (corrupção!) Causam opressão (opressão!) causam inflação (inflação!)

${ }^{16}$ Em 1979, Fela Kuti se candidatou à presidência da Nigéria nas primeiras eleições num período de mais de uma década, porém sua candidatura foi impugnada e a perseguição feita a ele, aos familiares e amigos continuou incessante.
} 
novas formas de imperialismo menos evidentes, muitas vezes, não se consegue (ou não se quer) atribuir às estratégias de discurso a importância que lhe é devida. Segundo Foucault “o discurso não é simplesmente aquilo que traduz as lutas ou os sistemas de dominação, mas aquilo por que, pelo que se luta, o poder do qual nos queremos apoderar”. (Foucault, 1996, p. 10) Ou seja, o poder do discurso está presente no cotidiano, legitimando ou esvaziando ideologias para os mais diversos fins.

Fela foi espancado e preso inúmeras vezes no decorrer da vida por diferentes governos totalitaristas que tomaram conta da Nigéria, desde sua independência. Em agosto de 1997, Fela Kuti faleceu devido a complicações provenientes do HIV e mesmo com 77 discos lançados, o músico chegou ao fim da vida falido. Suas canções foram proibidas de ser veiculadas nas rádios pelo governo nigeriano. E por mais tentativas de silenciamento que tenha sofrido, suas atitudes e, sobretudo, sua mensagem registrada em sua música serve de inspiração para diversos músicos e ativistas da causa negra, dentro e fora da África ainda hoje.

\section{Voukoum: os tambores como arma}

As pessoas da última categoria, os últimos dos últimos, os negros malvados, os negros da floresta são aqueles cujos cachorros cascas pelo rabo. Somos nós. Os sujeitos malvados são aqueles que falam mal, os negros mal vestidos, os negros sujos, aqueles que marcham errado. Somos nós. Os negros que expressam sempre em crioulo, os negros idiotas, os negros que não tem alma, os negros que pouco frequentam a escola. Somos nós, os negros antiquados, negros tuberculosos, negros atrofiados, os negros que tem pés grandes, negros com ferimentos, os negros “chofi". Somos nós. Os negros que comem a banana plantada, a fruta pão, o inhame ambabon, os negros que comem bacalhau e que comem a boca do porco salgado, os negros que comem os menores peixes. Somos nós. É assim que nós somos no fundo. (Perlier \& Factory, 2012)

Diferentemente das outras duas manifestações analisadas, à luz de trajetórias individuais, o Voukoum é uma manifestação popular desempenhada por cidadãos guadalupenses de origem africana. A ilha de Guadalupe, localizada no mar do Caribe, foi colonizada pela França e ainda hoje não alcançou sua independência. Desde 1946 é considerada departamento ultramarino francês.

O Mouveman Kiltirel Voukoum (Movimento Cultural Voukoum) surgiu na década de oitenta, na capital guadalupense Basse-Terre. Voukoum, palavra de origem crioula, cujo significado é "bagunça", "barulho", foi escolhida para dar nome ao movimento que surge como uma tentativa da população em manifestar sua insatisfação perante a situação política guadalupense, buscando salvaguardar a cultura afrodescendente 
frente às tentativas de assimilação francesa. Além disso, é o nome do ritmo tocado pelos manifestantes em suas marchas. Os músicos têm como base o Gwo Siwo, ritmo ancestral basseterrense, influenciado por ritmos trazidos pelos imigrantes haitianos e dominicanos, além de adaptações instrumentais para que se possa tocar e marchar simultaneamente.

Devido aos séculos sob o regime francês, inúmeros guadalupenses consideram as manifestações locais ilegítimas frente às práticas de matriz europeia aportada na ilha via franceses. No documentário francês Voukoum, dirigido por François Perlier, uma professora relata que muitas vezes a criança é proibida de falar o crioulo em casa. Por se tratar de um idioma ${ }^{17}$ de tradição oral, diversos elementos são perdidos. Por isso, ela se dispõe a ensinar a escrita do crioulo em algumas escolas, buscando transmitir o ensinamento das canções de Voukoum.

Nós estamos num período de reivindicação. Que todas as pessoas do Voukoum que marcham connosco e que consideram que nós estamos num desfile ordinário, estão enganadas. É preciso entender que os tambores são nossa arma principal, então é preciso cantar, marchar e permanecer legítimo. (Perlier \& Factory, 2012)

Um dos episódios que compõe a narrativa proposta pelo documentário, trata de uma greve geral liderada pela "Unidade Contra os Privilégios" (LPK), em 2009. As reivindicações que pautavam o movimento eram o aumento constante do custo de vida, a alta taxa de desemprego entre os jovens e a desigualdade social. Na marcha de reivindicação, os tambores do Voukoum estiveram presentes, fato que imbricou aos clamores de ordem econômica, as reivindicações identitárias e de reconhecimento histórico presente no discurso dos integrantes do movimento político musical.

O Voukoum também realiza oficinas buscando ensinar aos jovens guadalupenses não só a prática com instrumentos, mas também os elementos que compõe a cultura de resistência em Guadalupe. Os agentes buscam salvaguardar elementos da memória não-oficial, e lutam por espaço para fazer valer a "história subterrânea" colocando-a em disputa pelas suas identidades, sua memória, enfim sua cultura como parte constitutivamente importante da construção social guadalupense.

\footnotetext{
${ }^{17}$ Os critérios que levam a que um conjunto de dialetos seja considerado uma língua autônoma e não uma variedade de outra língua são frequentemente subvertidos por motivos políticos. A atribuição aos diferentes tipos de crioulo a classificação de dialeto, alegando que suas origens têm base em corruptelas de línguas oficiais é recorrente (cabe aqui frisar que o português, o francês, o espanhol, o italiano e romeno, classificados como línguas, são corruptelas do latim). Classifico, nesse artigo, o crioulo como língua.
} 


\section{Conclusão}

As músicas, sobretudo as canções, e seu potencial de capilaridade são ferramentas fundamentais na difusão dos discursos. Nos episódios analisados no decorrer deste artigo notamos como as práticas musicais trabalham conjuntamente à produção de discurso tradicional na difusão das mensagens cunhadas. Williams (1971), analisando o papel na arte e pensamento nos embates entre culturas hegemônicas e contrahegemônicas questiona o que, até então, era defendido por parte dos teóricos marxistas: a arte não é puramente reflexo do mundo real, visto que a superestrutura não é determinada pela estrutura, ambas estariam juntas no processo de produção de relações sociais.

Tanto o Reggae jamaicano, quanto o Afrobeat e o Voukoum são criações que surgem de experiências concretas, onde seus agentes estavam em busca de um significado social diferente do imposto pelas culturas dominantes, até então estabelecidas. "A realidade de qualquer hegemonia, no sentido político e cultural ampliado, é de que, embora por definição seja sempre dominante, jamais será total ou exclusiva.” (Williams, 1971. p. 116). Os discursos emergentes analisados vêm reiterar que nenhuma hegemonia é monolítica, propondo mais que uma alternativa, uma contraposição à cultura dominante.

O formato em que o contra discurso se solidifica pode variar, porém as manifestações em forma de prática artística são uma constante no decorrer da história. Após conseguir a independência junto à Espanha, por exemplo, surge em Cuba uma série de manifestações artísticas, à procura do reconhecimento de uma identidade nacional. Apesar da instauração da república, Cuba seguia com uma lógica política colonial devido à Emenda Platt1 ${ }^{18}$. Com essa "substituição de metrópole" os discursos a respeito da incapacidade da população cubana de se autogerir "decentemente", devido à questão racial implicou na insurgência no movimento intitulado afrocubanismo.

Los médicos, higienistas y científicos crearon un andamiaje necessário para afirmar que una Cuba mestiza y racionalmente diversa era una entidad viable, no condenada fatalmente a la subordinación y el atraso perpétuos. Lo que los científicos explicaron en los círculos y revistas académicas, los escritores y artistas lo divulgaron utilizando el linguaje literário, la pintura, la escultura, el baile y la música. Este movimento artístico, conocido como Afrocubanismo, utilizo los llamados "motivos negros" - como fueron designadas en el período las expresiones

\footnotetext{
18 A chamada Emenda Platt foi um dispositivo legal, inserido na Carta Constitucional de Cuba, que autorizava os Estados Unidos a intervir naquele país a qualquer momento em que interesses recíprocos de ambos os países fossem ameaçados. Desta forma, na prática, Cuba passou a ser um protetorado estadunidense.
} 
culturales de los afrocubanos - para crear un nuevo discurso cultural que se presentó a si mismo y fue generalmente percebido como autenticamente cubano. (...) La defesa de la cultura nacional era vista como una manera de detener la creciente americanización de la isla. (De la Fuente, 2001, pp. 252-253) ${ }^{19}$

Outro exemplo onde a cultura emergente se propôs a disputar significação social através de práticas artísticas, se deu nos próprios Estados Unidos com o Partido dos Panteras Negras. Em entrevista ao Brasil de Fato, a ex-ativista do movimento, Ericka Huggins destaca a importância dos jornais, pôsteres e imagens como ferramentas de ressonância, onde o discurso partidário era veiculado.

Porque muitas pessoas não podiam ler ou escrever, e a arte fala sem precisar de palavras. Nós críamos arte para a causa do povo e não arte pela causa da arte. Era muito importante entender as coisas como parte do mundo real, e não simplesmente como uma retórica política vazia. Queríamos que as pessoas entendessem como pensar sobre o mundo a partir da própria experiência. E queríamos que elas vissem a si mesmas como bonitas. Especialmente porque o mundo inteiro as dizia que eram feias e estúpidas. Não rebaixávamos ninguém. Não queríamos diminuir as outras raças ou os outros para nos fazer brilhar. Isso é o que o racismo faz: umas pessoas parecerem ruins para outras parecerem boas. (Brasil de Fato, 2013)

Através de um processo de resgate das tradições, as manifestações contra hegemônicas em tela se utilizam de uma série de elementos formadores da memória não oficial para, no presente, fazerem emergir histórias, até então, subterrâneas. Nesse processo, a produção musical é fundamental para a longevidade e ressonância dos discursos. Da mesma forma que o som tem a capacidade de invadir os mais diversos territórios por precisar apenas das partículas presentes no ar para se propagar, os discursos emergentes justapostos às músicas transcendem os anos, os limites estabelecidos pelas barreiras da memória oficial e das narrativas dominantes; ecoando enquanto dialogar com outros indivíduos por meio da tradição ou da identificação.

\section{Referências bibliográficas}

Albuquerque, C. (1997). O Eterno Verão do Reggae. São Paulo: Ed.34.

Bhabha, H. (2013). O Local da Cultura. Belo Horizonte: UFMG.

\footnotetext{
${ }^{19}$ Os médicos, higienistas e cientistas criaram uma maneira necessária para afirmar que uma Cuba mestiça e racionalmente diversa era uma entidade viável, não condenada fatalmente à subordinação e ao atraso perpétuo. O que os cientistas explicaram nos círculos e revistas acadêmicas, os escritores e artistas divulgaram utilizando a linguagem literária, a pintura, a escultura, a dança e a música. Este movimento artístico, conhecido como Afrocubanismo, utilizou os chamados "motivos negros" - como foram designadas no período as expressões culturais dos afrocubanos - para criar um novo discurso cultural que foi apresentado a si mesmo e foi de maneira geral percebido com autenticamente cubano. (...) A defesa da cultura nacional era vista com uma maneira de deter a crescente americanização da ilha.
} 
Bourdieu, P. (2001). O Poder Simbólico. Rio de Janeiro: Bertrand Russel.

Brasil de Fato. (2013) "Esconder o racismo não o faz ir embora". Obtido em 16 de outubro de 2013 de Brasil de Fato: http://www.brasildefato.com.br/node/26147

Césaire, A. (1978). Discurso Sobre o Colonialismo. Lisboa: Livraria Sá da Costa Editora.

De la Fuente, A. (2001). Una nación para todos: Raza, desiguald y política em Cuba. 19oo-20oo. Madrid: Editorial Colibri.

Fanon, F. (2008). Peles Negras, Máscaras Brancas. Salvador: EDUFBA.

Foucault, M. (1996). A Ordem do Discurso. São Paulo: Edições Loyola.

Hall, S. (2003). Da diáspora: Identidades e Mediações Culturais. Belo Horizonte: UFMG.

Moore, C. (2011). Fela: esta vida puta. Belo Horizonte: Nandyala.

Pollak, M. (1992). Memória e Identidade Social. Estudos Históricos, Rio de Janeiro, vol.5, n.10.

Seeger, A. (1977). Por Que os Índios Suya Cantam para as Suas Irmãs? In G. Velho (org) Arte e Sociedade, ensaios de sociologia da arte. Rio de Janeiro: Zahar, pp. 39-63.

Tumblr. (2013) Voukoum. Obtido em 16 de outubro de 2013 de Tumblr: http://voukoum.tumblr.com/mkv

Velho, G. (2001). "Biografia, trajetória e mediação". In K. Kuschnir, \& G. Velho (org). Mediação Cultura e Política. Rio de Janeiro: Aeroplano, pp. 15-28.

Wikipedia. (2013) Emenda Platt. Obtido em 16 de outubro de 2013 de Wikipedia: http://pt.wikipedia.org/wiki/Emenda Platt

Wikipedia. (2013) Malgaxes. Obtido em 27 de setembro de 2013 de Wikipedia: http://pt.wikipedia.org/wiki/Malgaxes

Wikipedia. (2013) Rude Boy. Obtido em 30 de setembro de 2013 de Wikipedia: http://pt.wikipedia.org/wiki/Rude boy

Williams, Raymond.(1971). Marxismo e Literatura. Rio de Janeiro: Zahar.

\section{Filmes}

Perlier, F. (Realizador) (2012). Voukoum. [Filme-Vídeo]. Produção de Réel Factory, Direção de François Perlier. França. 1 DVD, 52 min. Cor. Som.

\section{Discos}

Bob Marley \& The Wailers - Catch a Fire (1973) Island Records.

Bob Marley \& The Wailers - Uprising (1980) Island Records.

Fela Ransome Kuti e África 70 - Expensive Shit (1975) Soundwork Shop

Fela Anikulapo Kuti and The Africa 70 - Opposite People (1977) Decca Afrodesia

Fela Anikulapo Kuti and The Africa 70 - International Thief Thief (1979) Kalakuta 
Kyoma Silva Oliveira é mestrando em Cultura e Territorialidades pelo Programa de Pós-graduação da Universidade Federal Fluminense (UFF). Possui graduação em Produção Cultural pela mesma instituição (2012). Foi auxiliar de pesquisa no curso de capacitação em inventário de patrimônio cultural no projeto São Tomé e Príncipe plural: sua gente, sua história, seu futuro - Ações programáticas em comunicação e Cultura em novembro de 2012. Tem experiência na área dos Estudos Culturais, com estudos e pesquisas em torno da música, mediação, hibridação, identidade e estudos pós-coloniais.

kyomaoliveira@gmail.com 